\title{
Reduced Expression of Bax in Small Cell Lung Cancer Cells is NOT SufFiCiENT TO InduCE Cisplatin-RESISTANCE
}

\author{
J. Biagosch, R. M. Huber, A. Bergner \\ Department of Pulmonary Medicine, Medizinische Klinik-Innenstadt, Ludwig-Maximilians-University, Munich, Germany
}

\begin{abstract}
Resistance to cisplatin in the course of chemotherapy contributes to the poor prognosis of small cell lung cancer (SCLC). B cell lymphoma-2 is the founding member of a large family of proteins that either promote or inhibit apoptosis. We aimed at investigating if the pro-apoptotic members Bad, Bax, Bim and Bid are involved in cisplatin-resistance.

Cisplatin-resistance in the SCLC cell line H1339 was induced by repetitive exposure to cisplatin. Protein expression was quantified by Western Blot and immuno-fluorescence analysis. Protein expression was altered using siRNA interference.

Four "cycles" of $0.5 \mu \mathrm{g} / \mathrm{ml}$ cisplatin led to partial cisplatin-resistance in $\mathrm{H} 1339$ cells. The expression of $\mathrm{Bad}$, Bim and Bid was comparable in naïve and resistant cells while the expression of Bax was reduced in the resistant clone. But, reducing Bax expression in naïve cells did not lead to altered cisplatin sensitivity neither in H1339 nor in H187 SCLC cells.

We conclude that the reduced Bax expression after exposure to cisplatin is not sufficient to induce cisplatin-resistance in SCLC cells.
\end{abstract}

\section{INTRODUCTION}

In the industrial nations, lung cancer is the leading cause of cancer death [1]. Small cell lung cancer (SCLC) is the most aggressive histological pattern of lung cancer. Platin-based therapy regimens have become the backbone of small cell lung cancer chemotherapy with cisplatin being widely used. Firstline chemotherapy with cisplatin often leads to encouraging responses, but, in the course of the treatment, resistance to cisplatin is frequently observed. Possible mechanisms of resistance to cisplatin have been extensively studied and more than 100 proteins have been suggested to be involved [2, 3]. However, a satisfying clarification of the underlying mechanisms is still lacking and none of the proposed proteins has ever been proven to be clinically relevant. Therefore, the problem of the development of cisplatin-resistance in lung cancer still remains unresolved.

B cell lymphoma-2 (Bcl-2) is the founding member of a large family of proteins that either promote or inhibit apoptosis [4, 5]. The family is typically divided into three groups according to structural homology and function. The first group includes anti-apoptotic proteins with $\mathrm{Bcl}-2$ being the one that has been stud- ied to the greatest extent. The second group is constituted by pro-apoptotic proteins including Bcl-2-associated $\mathrm{X}$ protein (Bax). The third group is also proapoptotic and encompasses Bcl-2 homology 3 (BH3)only proteins, including Bcl-2-interacting mediator of cell death (Bim), Bcl-2 antagonist of cell death (Bad), and $\mathrm{BH} 3$ interacting domain death agonist (Bid).

In our study we aimed at investigating if altered expression of pro-apoptotic members of Bcl-2 family of proteins is involved in cisplatin-resistance in SCLC cells.

\section{Methods}

\section{MATERIALS}

Cell culture reagents were obtained from Life Technologies (Eggenstein, Germany). Other reagents were bought from Sigma-Aldrich (Deisenhofen, Germany) unless stated otherwise. The human SCLC cell line H1339 was purchased from DSMZ, Braunschweig, Germany. The human SCLC cell line H187 was kindly provided by Prof. Gudermann, Department of Physiology, Ludwig Maximilians University, Munich.

\section{Survival Curves}

Tumor cells were seeded in $25 \mathrm{~cm}^{2}$ cell culture flask and cultured for $24 \mathrm{~h}$. Next, cells were $3 \mathrm{~h}$ exposed to $1 \mu \mathrm{M}$ cisplatin analogue to the plasma concentration of unbound cisplatin in humans (6). Cell viability was evaluated by trypan blue exclusion cell counting $24 \mathrm{~h}$ to $96 \mathrm{~h}$ after the exposure and expressed as percentage of untreated control cells.

\section{Western Blot AnALYsis}

H1339 cells were washed twice with ice-cold phosphate-buffered saline (PBS; $10 \mathrm{mM}, \mathrm{pH}$ 7.4) and scraped in $0,02 \%$ EDTA solution. The cell suspensions were treated according to the manufacturer's protocol using the Cytobuster Protein Extraction Reagent for soluble proteins (Merck Biosciences, Germany). The extracts were collected, aliquoted and then stored at $-20^{\circ} \mathrm{C}$ until use with Western Blot analysis. The protein concentrations of the extracts were determined with the Non-Interfering Protein Assay Kit according to the manufacturer's protocol (Merck Biosciences, Germany). The extracts were treated with Laemmli sample buffer (at a final concentration of 
32,5 mM Tris, 2,5\% ß-mercaptoethanol, 1\% SDS and $12,5 \%$ glycerol) at $85^{\circ} \mathrm{C}$ for $10 \mathrm{~min}$ and separated by SDS-PAGE on a $10 \%$ Bis-Tris gel (Invitrogen, Canada). Staining was performed using specific antibodies (Bcl-2 Family Rabbit Monoclonal Antibody Sample Kit, Epitomics Inc., USA: Bcl-2 dilution 1:1000, Bcl-x dilution 1:1000, Bad dilution 1:2000, Bag-1 dilution 1:1000, Bak dilution 1:2000, Bax dilution 1:2000, Bim dilution 1:1000, Bid dilution 1:1000, Mcl-1 dilution $1: 1000$ ) and secondary antibody (goat anti-rabbit IgG (HRP), Santa Cruz Biotechnology, USA, dilution 1:5000).

B-Actin staining served as loading control (mouse anti-B-Actin HRP, Abcam, dilution 1:5000). Antibody complexes were visualized using Hyperfilm ECL chemiluminescence (Amersham Biosciences, UK) and evaluated using the "Image-J" analysis software.

\section{IMMUNO-FLUORESENCE}

H1339 cells were grown on microscope slides, fixed for $5 \mathrm{~min}$ in 100\% acetone and washed in sHBSS containing 10\% newborn calf serum (NCS). Antibodies were diluted 1:100 in sHBSS with 10\% NCS. The cells were incubated for $1 \mathrm{~h}$ at room temperature with monoclonal antibodies (Bcl-2 Family Rabbit Monoclonal Antibody Sample Kit, Epitomics Inc., USA). The cells were than washed in sHBSS with $10 \%$ NCS and incubated for $1 \mathrm{~h}$ at room temperature with Texas Red conjugated secondary anti-rabbit antibody (Santa Cruz Biotechnology, USA). The slides were inspected on a fluorescence microscope and the fluorescence intensity was quantified using the image analysis software "Scion".

\section{SMALl INTERFERING (SI) RNA TRANSFECTION}

Cells were transfected according to the manufacturer's protocol (Santa Cruz, Biotechnology, USA). The siRNA concentrations were adapted to ensure the desired decrease in protein expression without interfering with cell viability and growth as assessed by trypan blue staining and cell number. H1339 cells were transfected with $10 \mu \mathrm{M}$ Bax siRNA using the siRNA transfection reagent for $48 \mathrm{~h}$. Non-targeting siRNA served as control. After $48 \mathrm{~h}$, protein expression was quantified using Western Blot analysis. Four days after transfection, protein expression was again quantified to ensure stable transfection for the duration of the experiments with cisplatin.

\section{STATISTICS}

One-way or two-way ANOVA or "ANOVA repeated measurements" (combined with pairwise multiple comparisons) were performed using the "Sigma Stat" software (Jandel Scientific, Chicago, IL). A P value of less than 0.05 was considered statistically significant.

\section{RESULTS}

Analogue to the plasma concentration of unbound cisplatin in humans [6], H1339 cells were exposed to $0.5 \mu \mathrm{g} / \mathrm{ml}$ cisplatin for $3 \mathrm{~h}$. The cells that had survived

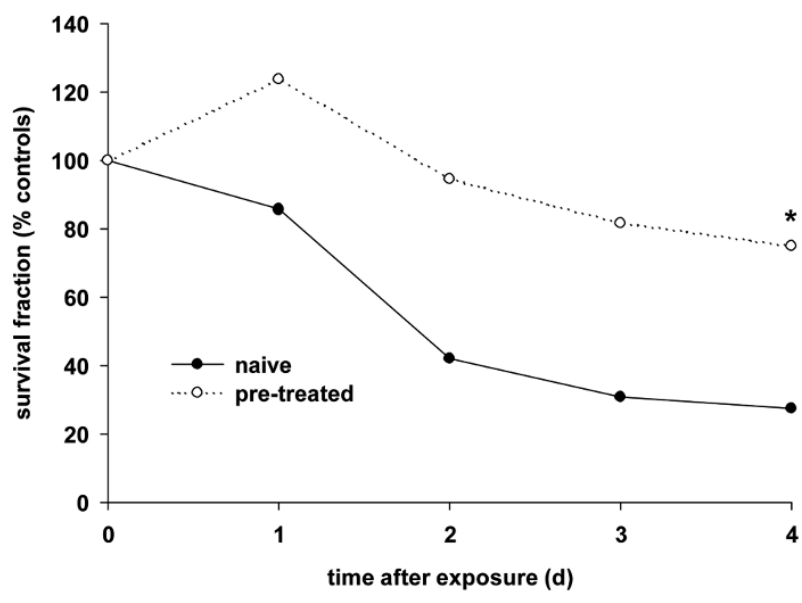

Fig. 1. H1339 human small cell lung cancer cells were exposed to $0.5 \mu \mathrm{g} / \mathrm{ml}$ cisplatin for $3 \mathrm{~h}$. The cells that had survived were allowed to recover for 7 days and were again exposed to $0.5 \mu \mathrm{g} / \mathrm{ml}$ cisplatin. After 4 "cycles", the survival after a 5 th exposure was compared to the survival of naive cells. Pre-treated cells showed an increased survival fraction compared to naïve cell $(*=\mathrm{P}<0.01)$.

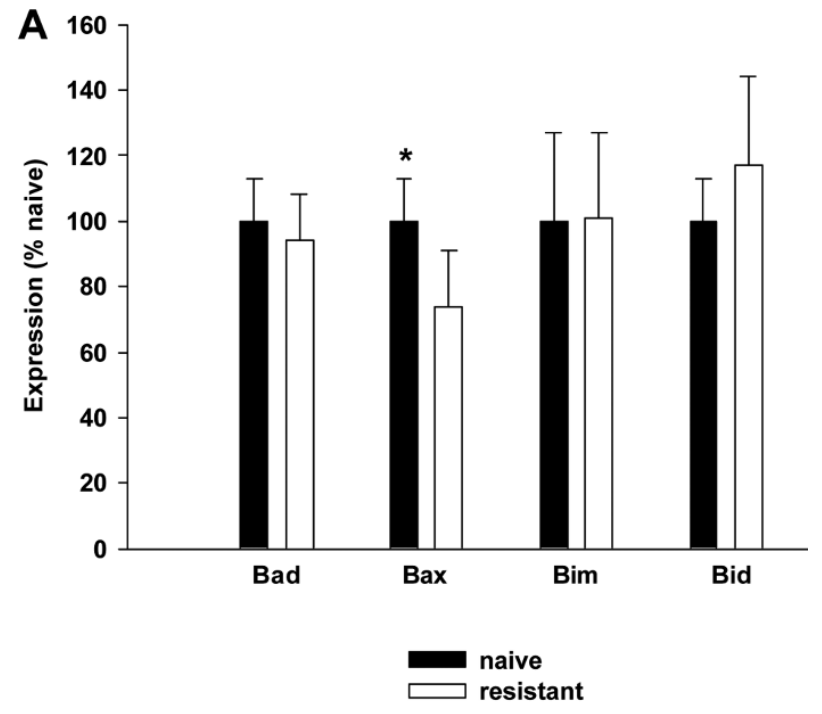

B
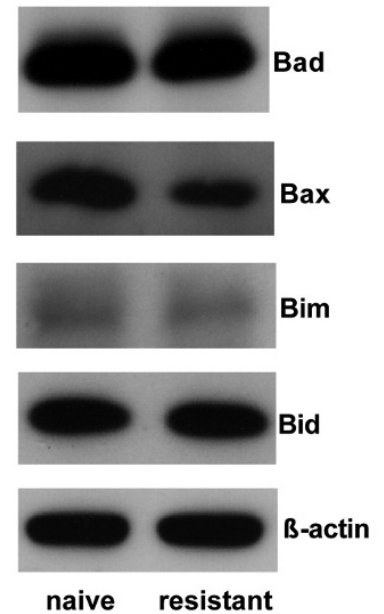

Fig. 2. The expression of members of the Bcl-2 family of proteins was studied in naïve and resistant H1339 cells using Western Blot. (A) The expression of Bax was lower in resistant cells $(\mathrm{n}=3, \mathrm{P}<0.05)$ while the expression of Bad, Bim and Bid showed no difference. (B) Representative Western Blots.

were allowed to recover for 7 days and were again exposed to $0.5 \mu \mathrm{g} / \mathrm{ml}$ cisplatin. After 4 "cycles", the survival after a 5 th exposure was compared to the sur- 


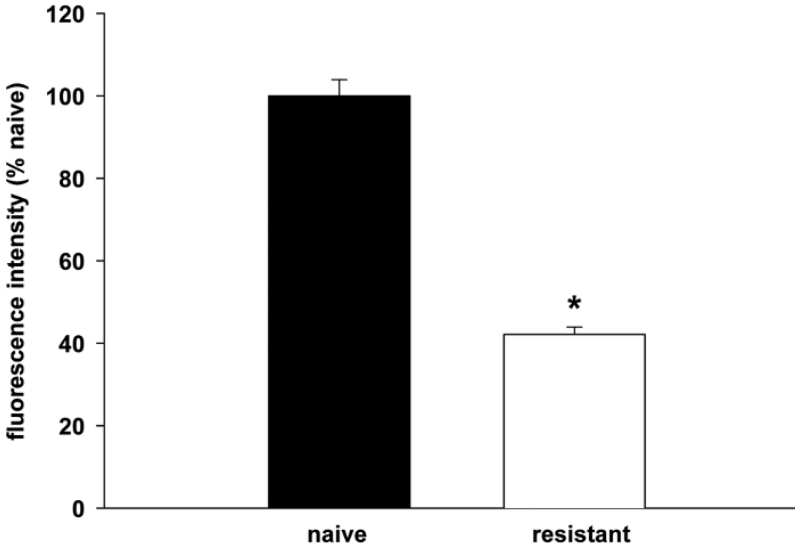

Fig. 3. The expression of Bax was assessed in naïve and resistant H1339 cells using immuno-fluorescence and found to be lower in resistant cells $(\mathrm{n}=20, \mathrm{P}<0.01)$.

\section{H1339 SCLC cells}
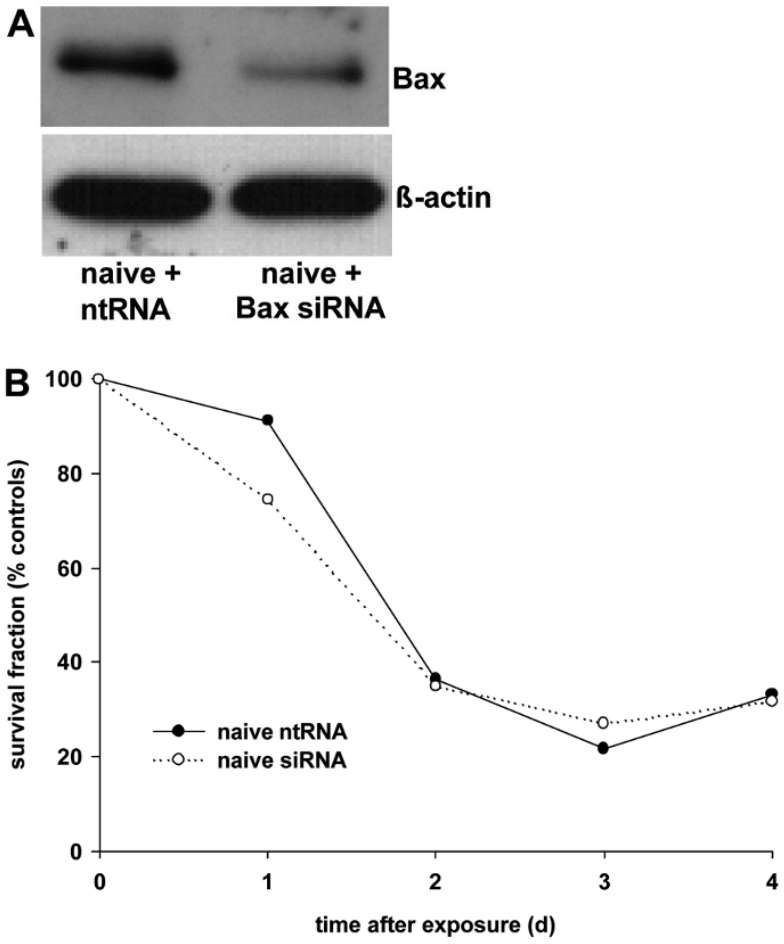

Fig. 4. A Naïve $\mathrm{H} 1339$ cells were $48 \mathrm{~h}$ treated with $10 \mu \mathrm{M}$ siRNA targeting Bax. As a result, the expression of Bax was reduced compared to naïve cells treated with non-targeting RNA. B Naïve H1339 cells with a reduced expression of Bax (naïve siRNA) and sham treated naïve $\mathrm{H} 1339$ cells (naïve ntRNA) were exposed to $0.5 \mu \mathrm{g} / \mathrm{ml}$ cisplatin for $3 \mathrm{~h}$. No difference in the cisplatin-sensitivity could be observed.

vival of naïve cells. The pretreated cells showed an increased survival fraction compared to naïve cells indicating partial resistance to cisplatin (Fig. 1). The cisplatin sensitivity was assessed for up to 5 passages but no change in cisplatin-resistance could be observed.

Next, the expression of the pro-apoptotic members of the Bcl-2 family of proteins Bad, Bax, Bim and Bid
H187 SCLC cells
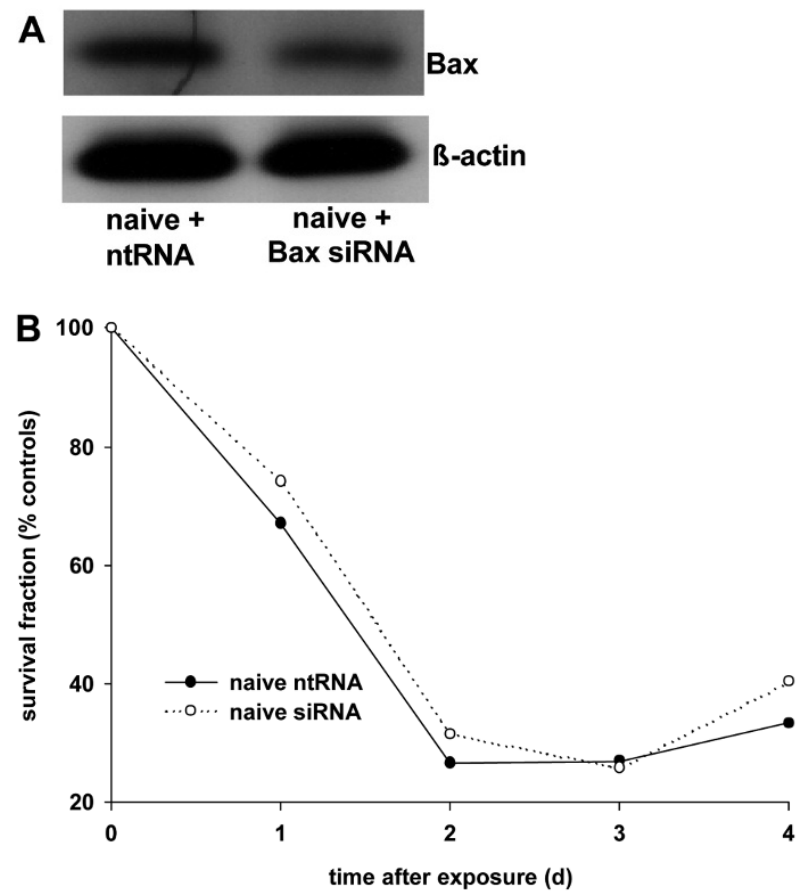

Fig. 5. A Naïve H187 SCLC cells were 48 h treated with 10 $\mu \mathrm{M}$ siRNA targeting Bax. As a result, the expression of Bax was reduced compared to naïve cells treated with non-targeting RNA. B Naïve H187 cells with a reduced expression of Bax (naïve siRNA) and sham treated naïve $\mathrm{H} 187$ cells (naïve ntRNA) were exposed to $0.5 \mu \mathrm{g} / \mathrm{ml}$ cisplatin for $3 \mathrm{~h}$. No difference in the cisplatin-sensitivity could be observed.

in naïve and resistant $\mathrm{H} 1339$ cells was assessed using Western Blot analysis. From the proteins tested, only Bax showed an altered expression with the expression being lower in the cisplatin-resistant clone (Fig. 2). To confirm the result of a reduced Bax expression obtained with Western Blot, we performed immuno-fluorescence analysis. Again, the fluorescence levels were lower in the resistant cells (Fig. 3).

We next aimed to investigate if the decreased expression of Bax in the resistant clone was causative for the cisplatin-resistance or an epiphenomenon. Using siRNA the expression of Bax was lowered in naive cells (Fig. 4A). But, no difference in cisplatin-sensitivity of naïve cells with reduced or unaltered Bax expression could be observed (Fig. 4B). Using a different SCLC cell line, H187, the experiments of the effect of reduced Bax expression on cisplatin sensitivity were repeated. Again, no difference in cisplatin sensitivity could be observed (Fig. 5).

\section{Discussion}

In this study, we have shown that repeated exposure to cisplatin led to cisplatin-resistance in H1339 SCLC cells. From the pro-apoptotic BCL-2 family of proteins members Bad, Bax, Bim and Bid only the expression of Bax was reduced in cisplatin-resistant H1339 cells. But, reducing Bax expression in naïve SCLC cells did not lead to altered cisplatin-sensitivity. 
Apoptotic stimuli lead to translocation of Bax and $\mathrm{Bad}$ to the mitochondria, which results in increased permeability of the mitochondrial double membrane [7]. This in turn causes release of cytochrome C, which initiates the caspase cascade finally leading to apoptotic cell death. Bim and Bid have been shown to bind to Bax thereby activating this pro-apoptotic protein [7].

Cisplatin resistant cells somehow escape the apoptotic stimulus caused by the cross linking of DNA base pairs through cisplatin. Multiple mechanisms have been proposed to cause cisplatin resistance $[2,3]$ including the intracellular $\mathrm{Ca}^{2+}$-homeostasis by our group [8]. Given their pro-apoptotic effects a reduced expression of Bad, Bax, Bim and Bid in cancer cells could cause cisplatin resistance. Indeed, we found the expression of Bax to be reduced using Western Blot analysis and immuno-fluorescence.

To test if the reduced expression in deed contributes to cisplatin resistance we could have increased the expression in resistant cells or decreased the expression in naïve cells. As siRNA constitutes a convenient and readily available tool we decided to do the latter. But, reduction in Bax expression did not alter cisplatin sensitivity. The interpretation of this finding could be that reduction in Bax expression is an epiphenomenon and not related to cisplatin resistance. Alternatively, Bax expression is one of several factors contributing to but not being sufficient for altered cisplatin sensitivity.

Sakakura et al. overexpressed Bax in MCF-7 breast cancer cells and increased thereby cisplatin sensitivity [9]. Also in breast cancer cell lines, Gibson et al. reported increased Bax expression following chemotherapy with cyclophosphamide [10]. These findings conflict with our data, but, however, different cell lines and chemotherapy were used.

Taken together we conclude that the reduced Bax expression after exposure to cisplatin is not sufficient to induce cisplatin resistance in SCLC cells.

\section{REFERENCES}

1. Alberg AJ, Ford JG, Samet JM (2007) Epidemiology of lung cancer: ACCP evidence-based clinical practice guidelines (2nd edition). Chest 132: 29S-55S.
2. Alt A, Lammens K, Chiocchini C, Lammens A, Pieck JC, Kuch D, Hopfner KP, Carell T (2007) Bypass of DNA lesions generated during anticancer treatment with cisplatin by DNA polymerase eta. Science 318: 967-970.

3. Stewart DJ (2007) Mechanisms of resistance to cisplatin and carboplatin. Crit Rev Oncol.Hematol. 63: 12-31.

4. Cory S and Adams JM (2002) The Bcl2 family: regulators of the cellular life-or-death switch. Nat.Rev Cancer 2: 647-656.

5. Rong Y and Distelhorst CW (2008) Bcl-2 Protein Family Members: Versatile Regulators of Calcium Signaling in Cell Survival and Apoptosis. Annu.Rev Physiol. 70:73-91.

6. de Jongh FE, Verweij J, Loos WJ, de Wit R, de Jonge MJ, Planting AS, Nooter K, Stoter G, Sparreboom A (2001) Body-surface area-based dosing does not increase accuracy of predicting cisplatin exposure. J Clin.Oncol. 19: 3733-3739.

7. Ghiotto F, Fais F, Bruno S (2010) BH3-only proteins: The death-puppeteer's wires. Cytometry A 77(1):11-21.

8. Schrodl K, Oelmez H, Edelmann M, Huber RM, Bergner A (2009) Altered $\mathrm{Ca}^{2+}{ }^{+}$-homeostasis of cisplatin-treated and low level resistant non-small-cell and small-cell lung cancer cells. Cell Oncol 31: 301-315.

9. Sakakura C, Sweeney EA, Shirahama T, Igarashi Y, Hakomori S, Tsujimoto H, Imanishi T, Ogaki M, Ohyama T, Yamazaki J, Hagiwara A, Yamaguchi T, Sawai K, Takahashi T (1997) Overexpression of bax sensitizes breast cancer MCF-7 cells to cisplatin and etoposide. Surg.Today 27: 676-679.

10. Gibson LF, Fortney J, Magro G, Ericson SG, Lynch JP, Landreth KS (1999) Regulation of BAX and BCL-2 expression in breast cancer cells by chemotherapy. Breast Cancer Res Treat. 55: 107-117.

Received: February 17, 2010 / Accepted: July 14, 2010

Address for correspondence:

Albrecht Bergner, MD, PhD

Division of Respiratory Medicine

Medizinische Klinik-Innenstadt

Ziemssenstr. 1

80336 Munich

Germany

Tel.: $\quad+49-89-5160-7545 / 2111$

Fax: +49-89-5160-5491

E-mail: albrecht.bergner@med.uni-muenchen.de 